\title{
Validation of low-cost pavement monitoring inertial sensor for urban road network
}

\author{
Giuseppe Loprencipe ${ }^{1, *}$, Flavio Guilherme Vaz de Almeida Filho ${ }^{2}$, Rafael Henrique de Oliveira ${ }^{2}$, and Salvatore \\ Bruno ${ }^{1}$
}

1 Department of Civil, Constructional and Environmental Engineering, Sapienza University, Via Eudossiana,18 - 00184 Rome, Italy; giuseppe.loprencipe@uniroma1.it (G.L.); salvatore.bruno@uniroma1.it (S.B.)

2 Department of Transportation Engineering, Polytechnic School of the University of São Paulo

Avenida Professor Almeida Prado, Travessa 2, 83 - 05508010 São Paulo, Brazil ; flaviovaz@usp.br (F.A.); rafa.oliveira@usp.br (R.O.)

* Correspondence: giuseppe.loprencipe@uniroma1.it; Tel.: +390644585112

\begin{abstract}
Road networks are monitored to evaluate their decay level and the performances regarding ride comfort, vehicle rolling noise, fuel consumption, etc. In this study, an Inertial Measurement Unit is proposed by using a low-cost three-axis Micro-Electro-Mechanical Systems accelerometer and a GPS instrument, which are connected to a Raspberry Pi Zero W board and embedded inside a vehicle to monitor indirectly the road condition. To assess the level of pavement decay, the comfort index $a_{\mathrm{wz}}$ defined by the ISO 2631 standard was considered. Considering $21 \mathrm{~km}$ of roads, with different levels of pavement decay, validation measures made using the proposed IMU, another preassembled IMU, and a Road Surface Profiler were performed. Therefore, comparisons between $a_{\mathrm{wz}}$ determined with accelerations measured on the two different IMU are made; in addition, also correlations between $a_{\mathrm{wz}}$, International Roughness Index (IRI), and Ride Number (RN) were performed. The results were shown very good correlations between the $a_{\mathrm{wz}}$ calculated with the proposed IMU and ones in the other IMU. In addition, the correlations between $a_{\mathrm{wz}}$ and IRI and RN were showed promising results, considering the use and the costs of the proposed IMU as a reliable method to assess the pavements decay in road networks where the use of traditional systems is difficult and/or not cheap.
\end{abstract}

Keywords: Pavement Monitoring; Inertial Measurement Unit; Urban Road; International Roughness Index; Ride Number; Ride Comfort.

\section{Introduction}

The management of infrastructural assets is a complex process that integrates many multidisciplinary strategies for the maintenance of public infrastructures [1]. Generally, the process interests on the later phases of the infrastructure's life cycle, but it would be better to integrate this process in the design phase [2].

This process aims to organize and implement strategies to maintain infrastructures enhancing their performance and extend their life span [3]. In fact, the infrastructures and in particular the transport ones are fundamental components for maintaining the quality of life in society and the efficiency of the Countries' economy.

Road pavement is a very important transport infrastructure asset that require an accurate assessment of the distresses for understanding how to fix them.

Pavement Management Systems (PMS) were employed by road agencies in the North America since the 1970s to manage their networks; these systems are evolved over the years to become reliable tools for the effective management of pavements for all road networks; since then their use has spread to all countries of the world [4].

Pavement distresses, causing surface unevenness, affect the vehicle operating cost [5], speed [6], riding comfort [7], safety [8], fuel consumption [9], wear of tires [10], noise 
[11] and pavement service life [12]. Pavement evaluation [13], in addition to the direct surface monitoring (by visual or automatic inspection) of appropriately categorized distresses, can take into account, alternatively or in addition, roughness or ride evaluation [14].

The pavement roughness is measured using high-performance equipment (contact or non-contact profilers), which detect road profiles along the pavement [15], and the acquired data are evaluated in terms of globally recognized indexes worldwide [16].

The most popular index used around the world to evaluate pavement roughness starting from the measured profile is the International Roughness Index (IRI) [17]. Many threshold values are available to depend on the length of the profile, the type of pavement (asphalt concrete or Portland Cement Concrete), and other pavement characteristics [1821]; other interesting researches proposed different threshold values considering the design speed of the road [22,23], so to accept higher IRI thresholds for the roads where the design speed is lower. The costs associated with sophisticated pavement evaluation equipment such as Mobile Measurement System (MMS) can be significant [24,25] relatively to the bargain budget of road agencies. For these reasons, the Road Surface Profilers (RSPs) are currently used to evaluate pavement roughness in nonurban road networks (roads outside administrative borders of cities with speed limits more than $70-80 \mathrm{~km} / \mathrm{h}$ ).

There are also operative problems that limits the use of RSPs in the urban road networks: these devices provide reliable results only at certain measurement speeds, generally higher than $30-35 \mathrm{~km} / \mathrm{h}$, which are not always possible in urban areas for various reasons (the presence of speed limits, the low planimetric radius, the many intersections, etc.). In addition, non-contact profilers need a launch segment free of obstacle that allows them to reach the predetermined survey speed, which further limits their application in an urban context. It should also be considered that the medium level of distress of urban pavements often does not allow the correct operation of these vehicles [14], which, as mentioned, are designed for nonurban roads.

There are alternative systems than can evaluate pavement roughness in indirect way considering indexes; these indexes can be determined starting from pavement profiles (i.e. Ride Number, RN) or considering methods involve the use of an accelerometer mounted in a moving vehicle. These last methods are potentially useful tools for pavement condition assessment in a cost-efficient way, but a preliminary calibration could be required to take into account the dynamic characteristics of the test vehicle and its speed [14].

Whatever system used to evaluate pavement roughness (using direct or indirect method) should be integrated at least with a high-precision GPS receiver to allow the correct localization and positioning of measurements on the road [26-32].

It is noted that the essential measurement systems necessary for the ride evaluation (three-axis accelerometers and GPS), are already available in the modern smartphones where they are suitably integrated and synchronized [33-39].

For this reason, many of these solutions were recently proposed over the world with different approaches: starting from accelerations, some apps try to estimate IRI along the surveyed road (divided into constant segments, 20-50-100 m) so to provide a typical evaluation (generally, using IRI) of pavement quality [40]. Other apps propose new indexes to evaluate pavement conditions [41] and other using its self-approach for classification [42].

To the shortcomings highlighted concerning the relevant devices, there is also the further difficulty that consists in the inadequateness of limit and thresholds for the various roughness indexes currently in use and previously described, which have been defined to correspond to particular needs and peculiarities of urban roads; first of all the low speeds, generally below $50 \mathrm{~km} / \mathrm{h}[22,43,44]$. Where an attempt has been made to overpass this lack, such as some limits of the IRI index defined according to the type of road or pavement, there is still some doubt to apply them in urban road network $[45,46]$.

In consideration of all these problems, the choice of the system monitoring and the assessment method for urban road pavements could be overcome by using an index that 
depends on the vertical accelerations measured inside a vehicle in motion considering its characteristics [47-50].

The solutions based on the survey of vertical accelerations inside the passenger compartment with a low-cost seem to be an interesting alternative to solve these difficult in the monitoring and assessment of urban pavement.

These sensors could arouse interest for those road network managers who do not yet have any continuous monitoring system for their pavements. In fact, they entrust the choice of maintenance strategies and the related interventions to procedures independent of monitoring (time-based maintenance) or in consequence of the occurrence of failures (run-to-failure maintenance) with serious losses of direct and indirect costs for the community.

Instead, it would be desirable to carry out maintenance referring to performancebased systems that allow identifying the appropriate time to perform maintenance interventions with respect to the conditions of the entire network and the available budget.

Considering the accelerations measured at a certain speed onboard a vehicle the whole vibration index called $a_{\mathrm{wz}}$ according to ISO 2631 [51] can be adopted associating with a level of pavement decay. In fact, the thresholds defined by the ISO 2631 standard in terms of comfort levels can be related, considering vehicle speed, to the different levels of decay pavement, obtaining a substantial correspondence with respect to the IRI and other analogous indexes [43].

In this study, an Inertial Measurement Unit was developed by using a low-cost threeaxis Micro-Electro-Mechanical Systems (MEMS) accelerometer and a GPS instrument, which are connected to a Raspberry Pi Zero W board [52] and embedded inside a vehicle for monitoring indirectly the road condition. To assess the level of pavement decay, the comfort index $a_{\mathrm{wz}}$ defined by the ISO2631 standard was considered.

Considering $21 \mathrm{~km}$ of roads, with different levels of pavement decay, validation measures made using both the proposed sensor, a pre-assembled IMU (Landmark 10 GPSA-150-10-200), and a RSP were performed. Therefore, comparisons between $a_{\mathrm{wz}}$ determined with accelerations measured on the proposed sensor and ones of the other more expensive IMU are made; in addition, also correlations between $a_{\mathrm{wz}}$, IRI and RN determined using respectively the proposed sensor and the RSP were performed. The results were shown very good correlations between the $a_{\mathrm{wz}}$ calculated with the sensor proposed and ones in the other IMU. In addition, the correlations between $a_{\mathrm{wz}}$ and IRI and RN were shown promising results, considering the use of the proposed sensor as a reliable method to assess the pavements decay in road networks where the use of traditional systems is complicated and/or not cheap.

\section{Materials and Methods}

In this section, the methods and procedures used for evaluating, indirectly and directly, pavement condition are described.

\subsection{Whole-Body Vibration-ISO 2631}

Starting from the vertical accelerations in the time domain, measured onboard the test vehicle, the root mean square (RMS) accelerations through the evaluation of the PSD can be determined for all the frequency range of interest for the human response to vibrations (between $0.5-80 \mathrm{~Hz}$ ), and analyzed by a spectrum of 23 one-third octaves bands. This procedure is specified by the technical standards currently in use $[53,54]$ and it is similar to other analysis to transform the signals measured in the time domain in spectrum in the frequency domain.

Once the RMS acceleration one-third octave spectrum is known ( $\boldsymbol{a}_{\boldsymbol{z}}=$ $\left(a_{z, 1}, a_{z, 1}, \ldots, a_{z, 23}\right)$, corresponding to the 23 frequencies proposed by ISO2631 $(0.5,0.63$, $0.8,1,1.25,1.6,2,2.5,3.2,4,5,6.3,8,10,12.5,16,20,25,32,40,50,64,80)$, it is possible to calculate the vertical weighted RMS acceleration $\left(a_{w z}\right)$ using Equation (1): 


$$
a_{w z}=\sqrt{\sum_{i=1}^{23}\left(W_{k, i} \cdot a_{z, i}\right)^{2}}
$$

where $W_{k, i}$ are the frequency weightings in one-third octaves bands for the sensor position, provided by the standards ISO2631 [51] and $a_{z, i}$ is the vertical RMS acceleration for the i-th one-third octave band. Then, the calculated values can be compared with the threshold values proposed by ISO 2631 for public transport (Table 1), in order to identify the comfort level perceived by users in all roads sections, also considering several speeds of transit.

Table 1. Comfort levels related to $a_{w z}$ threshold values as proposed by ISO 2631 for public transport.

\begin{tabular}{cc}
\hline $\boldsymbol{a}_{w z}$ values $\left(\mathrm{m} / \mathbf{s}^{2}\right)$ & Ride Number \\
\hline less than 0.315 & Not uncomfortable \\
$0.315-0.63$ & Little uncomfortable \\
$0.5-1.0$ & Fairly uncomfortable \\
$0.8-1.6$ & Uncomfortable \\
$1.25-2.5$ & Very uncomfortable \\
more than 2.5 & Extremely uncomfortable \\
\hline
\end{tabular}

Considering the real characteristics of the acceleration sensor used during the measure and analysis (the analysis time, $T$ and output data rate frequency, $f_{s}=1 / \Delta t$ in $\mathrm{Hz}$, where $\Delta t$ is the signal sampling), not all the 23 one-third octaves bands could be determined. At any rate, the evaluation of PSD was done using a DFT function in Matlab® and considering the Nyquist-Shannon sampling theorem [55]. In addition, to minimize the effects of performing DFT over a no integer number of cycles, the classic technique of Split-Cosine Bell windowing was used. In the Figure 1 an example of three different spectrum calculated starting from acceleration data are depicted.

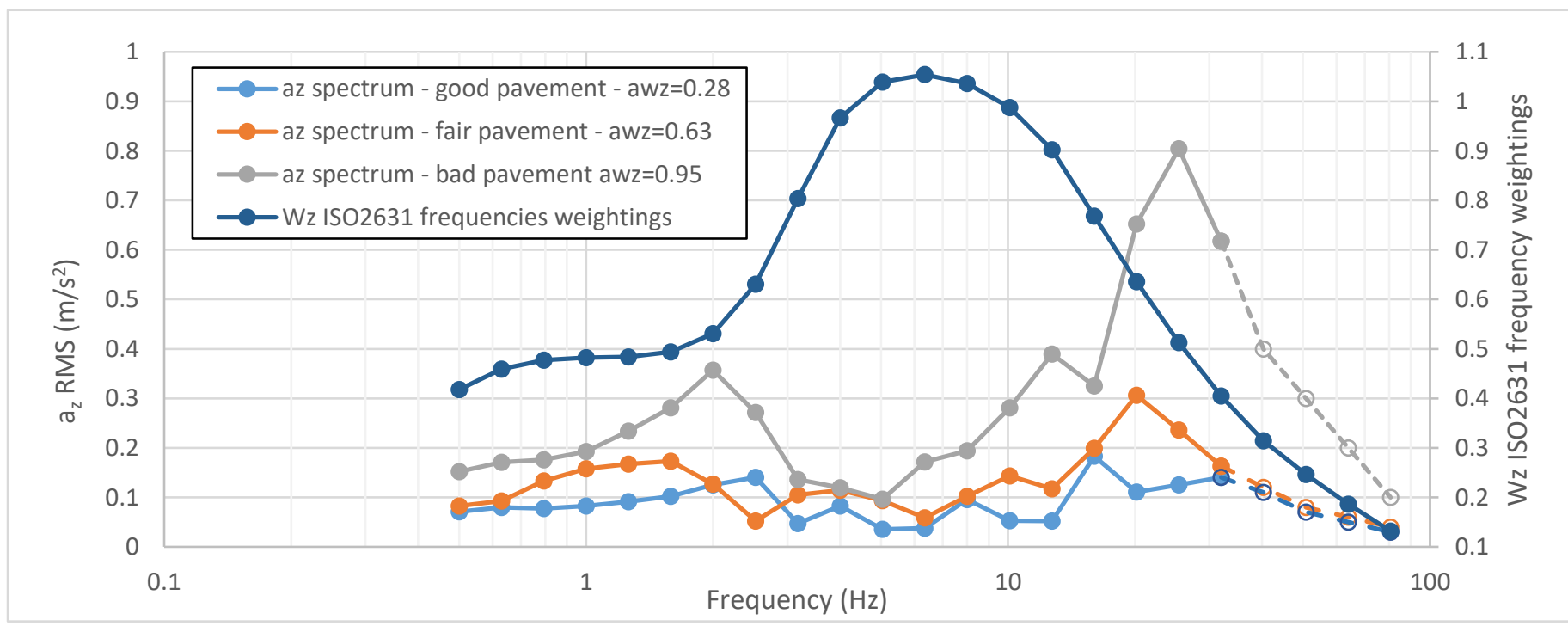

Figure 1. Three different spectrum calculated starting from acceleration and ISO2631 frequencies weightings curve.

In the Figure 1 is highlighted as the contribution in the $a_{w z}$ calculus of the last 4 values of the spectrum can be neglected, in consequence of the low values of the frequencies weightings curve $W z$. 
The ISO2631 was developed by the International Organization for Standardization (ISO) and is regarded to as a standard model adopted by several countries over the world. This standard provides several comfort levels (Table 1) introducing an overlapping zone between two adjacent ones because many factors (e.g., user age, acoustic noise, temperature, etc.) contribute to determine the degree to which discomfort could be noted or tolerated.

At any rate, the comfort levels proposed by ISO 2631 are adopted in many countries and they may be compared with the RMS values of the frequency-weighted vertical acceleration in the vehicle $a_{w z}$ obtained inside a vehicle, giving approximate indications of likely reactions to various magnitudes of overall vibration total values in public transport.

In order to define specific limits to be used by road agencies, it is necessary to link $a_{\mathrm{wz}}$ values to IRI ones as proposed by many researchers $[7,21,43,45,49,50]$. In this way, it is possible to relate comfort perception (also influenced by vehicle characteristics) with a parameter that represents the condition and performance of road pavements surfaces.

\subsection{International Roughness Index (IRI) - ASTM E 1926}

The IRI was elaborated from a World Bank study in the 1980s [56] and it is one of the most adopted index used to evaluate the pavement roughness. It is based on a mathematical model called quarter-car and was developed in order to assess the pavement condition relating to all the detrimental effects such as ride quality, increasing dynamic load, tyre rolling noise, fuel consumption, and the road safety.

Many decay curves have been proposed to predict the maintenance plan over time [57] and the consequent service life of the pavement knowing its operating conditions (traffic, climate, etc.) [58].

The calculation of IRI was performed using computer program that implementing the simulation of the mechanical model considering a profile according to the Equation (2):

$$
I R I=\frac{1}{L} \int_{0}^{L}\left|z_{s}-z_{u}\right| d x
$$

where $L$ is the length of the profile in $\mathrm{km}, V$ is the simulated speed set to $80 \mathrm{~km} / \mathrm{h}, z_{s}$ is the vertical displacement of the sprung mass in $\mathrm{m}$, and $z_{u}$ is the vertical displacement of the unsprung mass in $\mathrm{m}$. The final value is expressed in slope units (e.g., $\mathrm{m} / \mathrm{km}$ or mm/m). In the present work, the algorithm proposed by the ASTM E1926 standard [59] for IRI calculation was used.

As reported in [44], there is a high heterogeneity of IRI thresholds adopted around the world. In fact, IRI limit values mainly depends from several aspects: road surface type (i.e., asphalt or cement concrete pavements), road functional category, average annual daily traffic (AADT), legal speed limit and segment length considered for IRI calculation.

The most common segment length indicated in non-US countries is equal to $100 \mathrm{~m}$ [44] but frequently also length of $50 \mathrm{~m}$ and $20 \mathrm{~m}$ are adopted to better take into account the contribution of the single event bumps respect to distributed unevenness.

\subsection{Ride Number RN}

The Ride Number (RN) is result of a mathematical algorithm obtained using two longitudinal profiles that allows the estimation of the subjective ride quality perceived by road users.

It is quite used over the world and it is correlated to the perceived comfort experimented by user riding on roughness pavement.

The RN index is the result of an international research conducted in the 1980s and sponsored by The National Cooperative Highway Research Program (NCHRP), with the aim of analyzing how the characteristics of road profiles influence the ride comfort perceived by user road [60].

The RN thresholds were obtained determining how characteristics in road profiles were linked to subjective opinion about the road from interviewed users; it is possible 
evaluate the pavement condition using a 0-to-5 scale where correspond respectively to "impassable" and "perfect" pavement condition (Table 2).

Table 2. Ride Number Thresholds

\begin{tabular}{cc}
\hline Description & Ride Number \\
\hline Perfect & 5.0 \\
Very Good & 4.5 \\
& 4.0 \\
Good & 3.5 \\
& 3.0 \\
Fair & 2.5 \\
& 2.0 \\
Poor & 1.5 \\
& 1.0 \\
Very poor & 0.5 \\
Impassable & 0.0 \\
\hline
\end{tabular}

The RN calculus requires a pavement survey using a "Class I" profiler of two profiles, and two Profile Indexes (PILeft, $\left.P I_{\text {Right }}\right)$ were calculated adopting the algorithm reported in the ASTM E 1489 - 98 [61].

The calculation of $R N$ was performed by means of Equations (3) and (4):

$$
\begin{gathered}
P I=\sqrt{\frac{P I_{\text {Left }}^{2}+P I_{\text {Right }}^{2}}{2}} \\
R N=5 \cdot e^{-160 \cdot(P I)}
\end{gathered}
$$

With some exceptions, the wavelengths' range of interest for RN is similar to that of IRI, as reported in some researches [17], in consequence good correlations can be find between IRI and RN [12]. In particular, RN presents a higher sensitivity to low wavelengths than IRI, which has a greater sensitivity to wavelengths of $16 \mathrm{~m}$ or longer than RN.

\section{Device description}

\subsection{General architecture of the proposed sensor}

The proposed low-cost and easy-to-operate device has as main aspect its similarity with smartphones regarding sensors configuration, performance, and cost. Thus, the two devices assembled and set up for the described work are composed of the following consumer-grade components: a Raspberry single board microcomputer, a micro-electrical mechanical Inertial Measurement Unit, a mini Global Navigation Satellite System (GNSS) module, a power supply, and a flashcard. This section describes these components as follows and highlights the most important features regarding the described application.

\subsubsection{Raspberry Pi Zero W single-board microcomputer}

The Raspberry Pi Zero W is a low-cost single-board microcomputer of $6.5 \times 3.0 \mathrm{~cm}$ developed by Raspberry Pi Foundation for applications such as education and prototyping. This Raspberry model has a 512 RAM, a 1 GHz single-core microprocessor, and a 40pin general-purpose input/output (GPIO) [52]. It also has 802.11 wireless LAN (Wi-Fi) and Bluetooth connectivity, which simplifies re-mote control and data transmission without the need for uninstallation and reinstallation. The Raspberries used in the described tests run the Linux-based Raspbian operating system.

\subsubsection{Inertial Measurement Unit}


A micro-electrical mechanical (MEMS) based Inertial Measurement Unit (IMU) is a single chip multi-axis sensor that provides estimates at least linear accelerations and angular velocities and, thus, integrates accelerometer and gyroscope. Some versions of MEMS IMU single chips also integrate non-inertial sensors such as magnetometer and barometer. The recent MEMS technology progress focused on mobile gadgets has been yielding very low cost and very small smartphone-grade IMU units with a cost of about cents, size of about square centimetres, and satisfactory performance for non-critical applications. Thus, the main advantages of these inertial sensors when compared with traditional mechanical and solid-state sensors are the size reduction, the low power consumption and the low production cost [62].

For this research, we used the InvenSense MPU-9250, a 10 degrees-of-freedom module of $1,4 \times 1,4 \mathrm{~cm}$. This inertial module integrates the three-axis MEMS inertial sensors (accelerometer and gyro-scope) to a magnetometer and a pressure module BMP280 (a barometer plus a thermometer) [63,64]. The voltage readings from the inertial sensors are digitized using on-chip 16-bit resolution Analog-to-Digital Converters (ADC) for each axis, and this digital output is sent to the Raspberry through inter-integrated circuit (I2C) interface. Besides the raw measurements, the MPU-9250 module measures and has a digital motion processor that provides fused output for gesture recognition applications. Table 3 presents the main features of MPU-9250 accelerometer, gyroscope, and magnetometer.

Table 3. MPU-9250 accelerometer, gyroscope, and magnetometer main features [52].

\begin{tabular}{|c|c|c|c|}
\hline Property & Accelerometer & Gyroscope & Magnetometer \\
\hline Full-scale range & $\begin{array}{c}\text { User-programmable: }+-2,4,8 \\
\text { or } 16 \mathrm{~g}\end{array}$ & $\begin{array}{c}\text { User-programmable: } 250 \text {, } \\
500,1000 \text { or } 2000 \% \text { s }\end{array}$ & $+-4800 \mu \mathrm{T}$ \\
\hline Noise spectral density & $300 \mu \mathrm{g} / \sqrt{ } \mathrm{Hz}$ & $0.01 \% / \mathrm{s} / \sqrt{ } \mathrm{Hz}$ & - \\
\hline Sensitivity scale factor & $\begin{array}{c}\text { User programmable: } 16.384 \text {, } \\
8.192,4.096 \text { or } 2.048 \mathrm{LBS} / \mathrm{g}\end{array}$ & $\begin{array}{l}\text { User-programmable: } 131 \text {, } \\
\left.65.5,32.8 \text { or } 16.4 \mathrm{LBS} /\left(^{\circ} / \mathrm{s}\right)\right)\end{array}$ & $0.6 \mu \mathrm{T} / \mathrm{LSB}$ \\
\hline Output data rate & up to $4000 \mathrm{~Hz}$ & up to $8000 \mathrm{~Hz}$ & up to $8 \mathrm{~Hz}$ \\
\hline
\end{tabular}

The C++/Python library named RTIMULib [65] was used for sensors setup, initial calibration on Raspbian, and conversion of values form hexadecimal to floating-point representation. The following data is obtained: i) three-axial raw linear accelerations (including gravity) in the sensor frame, in g; ii) three-axial raw angular velocities in the sensor frame, in rad/s; iii) three-axial raw magnetic field in the sensor frame, in $\mu \mathrm{T}$; iv) pressure, in $\mathrm{hPa}$; v) height derived from the barometric calculation, in $\mathrm{m}$; vi) temperature, in ${ }^{\circ} \mathrm{C}$; vii) sensor attitude (roll, pitch, and yaw, in degrees). Regarding attitude data, angles are obtained by RTIMULib through Extended Kalman Filter (EFK) integrating inertial and magnetic data, a technique that adapts Kalman Filter to a nonlinear problem such as the attitude estimation.

The output data rate was set up at $100 \mathrm{~Hz}$ given the optimum performance on preliminary tests, the aimed data analyses, and the usual sample rate for medium-grade smartphones. However, the maximum mean sample rate effectively obtained during operation (> $10 \mathrm{~s}$ ) was about $83 \mathrm{~Hz}$ owing to hardware and software limitations.

3.1.3. Mini Global Positioning System (GPS) module

A U-blox mini Global Positioning System (GPS) module, NEO-6M model [66], positioning was used in each sensor set. This receiver performs single-point positioning using C/A Code of L1 frequency from GPS constellation, as well as obtains augmented from 
satellite-based augmentation systems. The single-point positioning technique using single L1 frequency and civilian code presents a typical horizontal position error of $13 \mathrm{~m}$ at a probability level of $95 \%$ under standard scenarios. Complementary, satellite-based augmentation systems (SBAS) corrections reduce satellite-related and ionospheric-related errors and improve integrity, availability, and continuity. However, satellite-based positioning quality can be degraded by environmental factors such as signal multipath, signal blockage, and atmospheric interference $[67,68]$. NEO-6M main features are presented in Table 4.

Table 4. U-blox NEO-6M mini GPS module main features [64].

\begin{tabular}{cc}
\hline $\begin{array}{c}\text { Satellite-based Augmentation } \\
\text { Systems (SBAS) }\end{array}$ & $\begin{array}{c}\text { Wide Area Augmentation System (WAAS), European Geosta- } \\
\text { tionary Navigation Overlay Service (EGNOS), and Multi-func- } \\
\text { tional Satellite Augmentation System (MSAS) }\end{array}$ \\
Maximum update rate & $5 \mathrm{~Hz}$ \\
Time-To-First-Fix $^{1}$ & Cold or warm start: $27 \mathrm{~s}$ \\
& Hot start: $2 \mathrm{~s}$ \\
Horizontal position error & Aided start: $<3 \mathrm{~s}$ \\
& GPS: $2.5 \mathrm{~m}$ \\
Velocity error $^{2}$ & SBAS: $2.0 \mathrm{~m}$ \\
Bearing error $^{2}$ & $0.1 \mathrm{~m} / \mathrm{s}$ \\
\end{tabular}

1 Satellites at $-130 \mathrm{dBm}$.

2 Circular Error Probability (CEP) 50\%, satellites at -130 dBm, obtained from 24-hour static position solution

The output rate for the GPS module was set up at $1 \mathrm{~Hz}$ regarding the performance during pre-liminary tests, and the sample rate for medium-grade smartphones. The lower sample rate in com-parison with IMU rate requires interpolation of PVT data using the OS timestamp as the key attribute. Furthermore, GPS and IMU data are recorded in separated files since it has the best performance un-der the abovementioned configuration.

The Python library called GPSD [69] allows for the acquisition, on Raspbian environment, of position, velocity, and time (PVT) data through US National Marine Electronics Association (NMEA) protocol. The following GPS data is obtained: geographic coordinates (latitude and longitude) of the acquisition point referred to WGS84 datum (GPS datum), geometric height, UTC time of the acquisition point, velocity, number of visible satellites, and uncertainty-related parameters.

Figure 2 shows the core components already assembled. The IMU module and the GPS module were connected to the processing unit and glued to the Raspberry case.
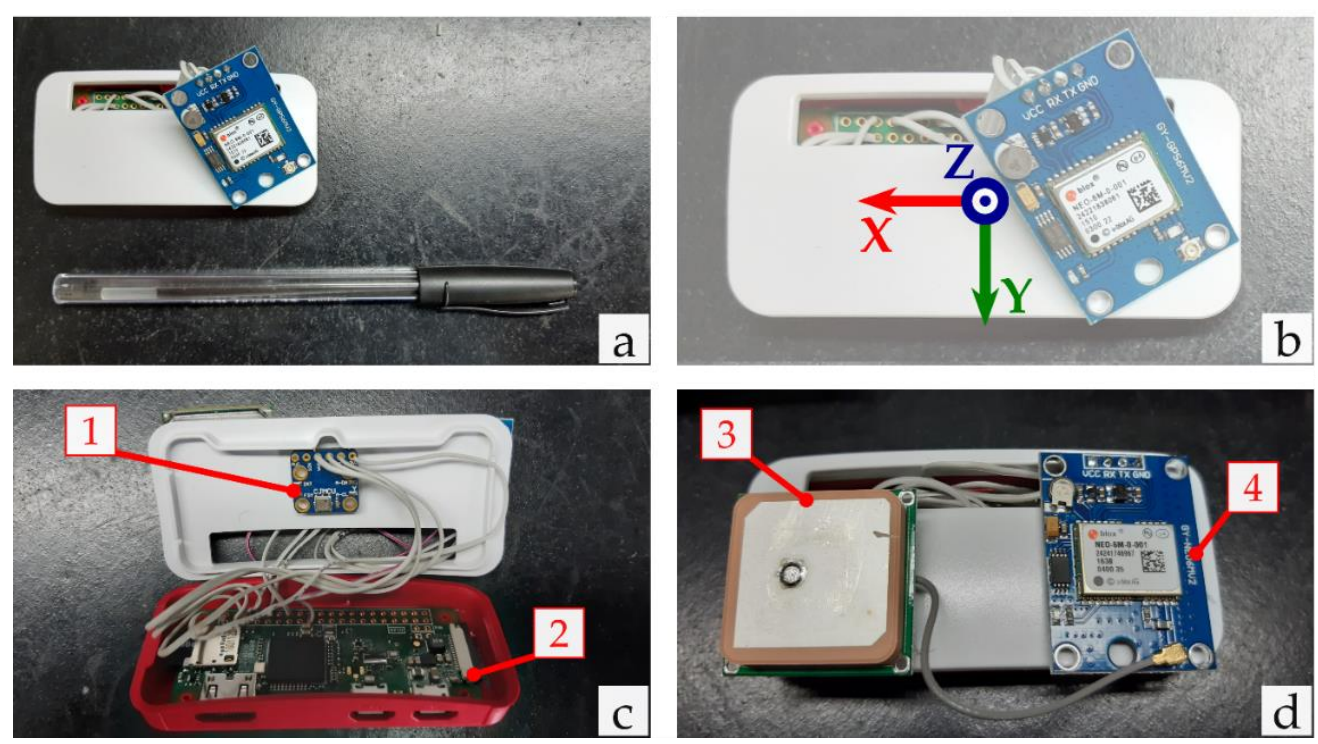
Figure 2. The core components of the developed device: (a) size comparison of the Raspberry + IMU module + GPS module assembly; (b) sensor axes orientation; (c) device with its case open and with a view of the IMU module (1) and the Raspberry Pi Zero W (2); (d) closed case with a view of the GPS antenna (3) and the u-Blox GPS module (4).

\subsubsection{Other components}

Each Raspberry operates with a 16 GB micro-SD used to store the operating system and the gathered data. Moreover, power is supplied by a portable rechargeable battery unit with 10,400 mAh capacity through a micro-USB port. Considering storage and power capacities under the aforementioned configuration, the sensor sets presented an autonomy of at least 50 hours during the preliminary test.

\subsection{LandMark 10 GPSA-150-10-200}

In order to validate the results of the measurements made with the proposed sensor on the same test road test also the pre-assembled inertial platform LandMark 10 GPSA150-10-200 was employed.

The most important product characteristics are summarized in the code name, that reporting the operating range of both gyroscopes $( \pm 150 \% \mathrm{sec})$ and accelerometers $\left( \pm 10 \mathrm{~g}^{\prime} \mathrm{s}\right)$ as well as the product type GPS/AHRS (Attitude Heading Reference System).

The main component parts of this instrument are:

- $\quad$ the Inertial Measurement Unit (IMU) (Figure 3a);

- $\quad$ the integrated GPS receiver (Figure 3b);

- $\quad$ the power supply to connect to a laptop (Figure 3c).

This connection also allows recording the data measured to a comma-separated values (CSV) file. The software named "GLAMR" to acquire the data have to be installed in a standard Notebook.

The Kalman filter is automatically implemented inside the LandMark 10 GPSA-15010-200; the Kalman filter is an efficient recursive filter that evaluates the state of a dynamic system starting from a series of measurements subject to noise. Its use allows to eliminate part of the background noise that could affect the measurements.

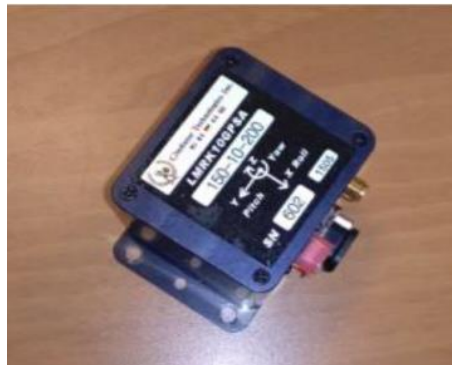

(a)

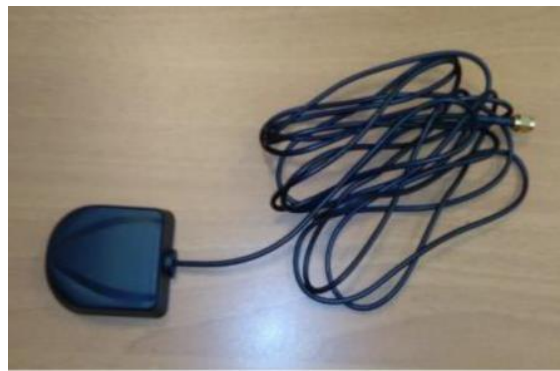

(b)

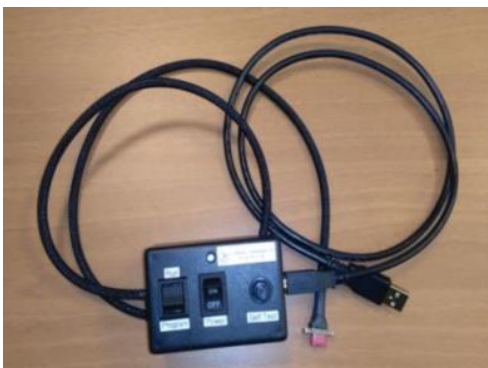

(c)

Figure 3. LandMark 10 GPSA-150-10-200 main component parts: IMU(a); the integrated GPS receiver (b); the power supply (c).

\subsection{Automatic pavement data-collection vehicle}

In order to validate the results of the measurements made with the proposed sensor on the same test roads, a Road Surface profiler was employed. For this purpose, a multifunction Mobile Measurement System was used thanks the support of the Laboratory of Road Materials and Maintenance of the Italian National Road Agency (Centro Sperimentale Strade di Cesano di ANAS S.p.A. Gruppo Ferrovie dello Stato Italiane)

This mobile laboratory named "Cartesio" was designed according to the Department of Road Maintenance of Italian National Roads Department (ANAS). The system has been operating since 2018 on the whole road network managed by ANAS. 
Mobile Mapping is the term that identifies the techniques of detection from moving vehicles; the data obtained from on-board sensors are georeferenced as a positioning and orientation system is mounted.

The main fields of application of this multifunction road-quality surveying instrument are updating of the road cadastre, road maintenance and the survey of infrastructure elements, networks and services that meet along the road axes.

The main components of this high-performance vehicle are:

- the positioning and orientation system so as to georeferenced the data collected from on-board sensors;

- $\quad$ on-board sensors (5 high resolution digital cameras; 2 LIDAR Laser Scanner; Laser Crack Measurement System (LCMS); 3 inertial profilometers);

- $\quad$ the synchronization system coordinated by a management system.

Other auxiliary systems are:

- $\quad$ the data storage system;

- $\quad$ the power supply system for equipment and documents.

All the components are permanently installed on a Fiat Ducato 290.

\section{Field Tests for system validation}

With the aim to validate the proposed IMU, some field tests were carried out using two identical prototypes of the device described in section 3.1; in this paper, these two IMUs can be distinguished with the code "SENSORS\#1" and "SENSORS\#2".

The accelerometer data recorded by the sensors placed inside test vehicles were processed using program code written in MATLAB ${ }^{\circledR}$ in order to get $a_{w z}$ index values every 1 second. For the acceleration signals, an analysis time of 2 seconds was considered, so, for each device, an overlap of the acceleration signals were obtained of 1 second.

The validation test was performed using all the devices at the same time identifying a total of about $21 \mathrm{~km}$ of roads (Figure 4) with flexible pavement located in the northern outskirts of Rome. The route started and ended at the same section; it was articulated on both urban and nonurban roads (Table 5) with one lane for each travel direction. 


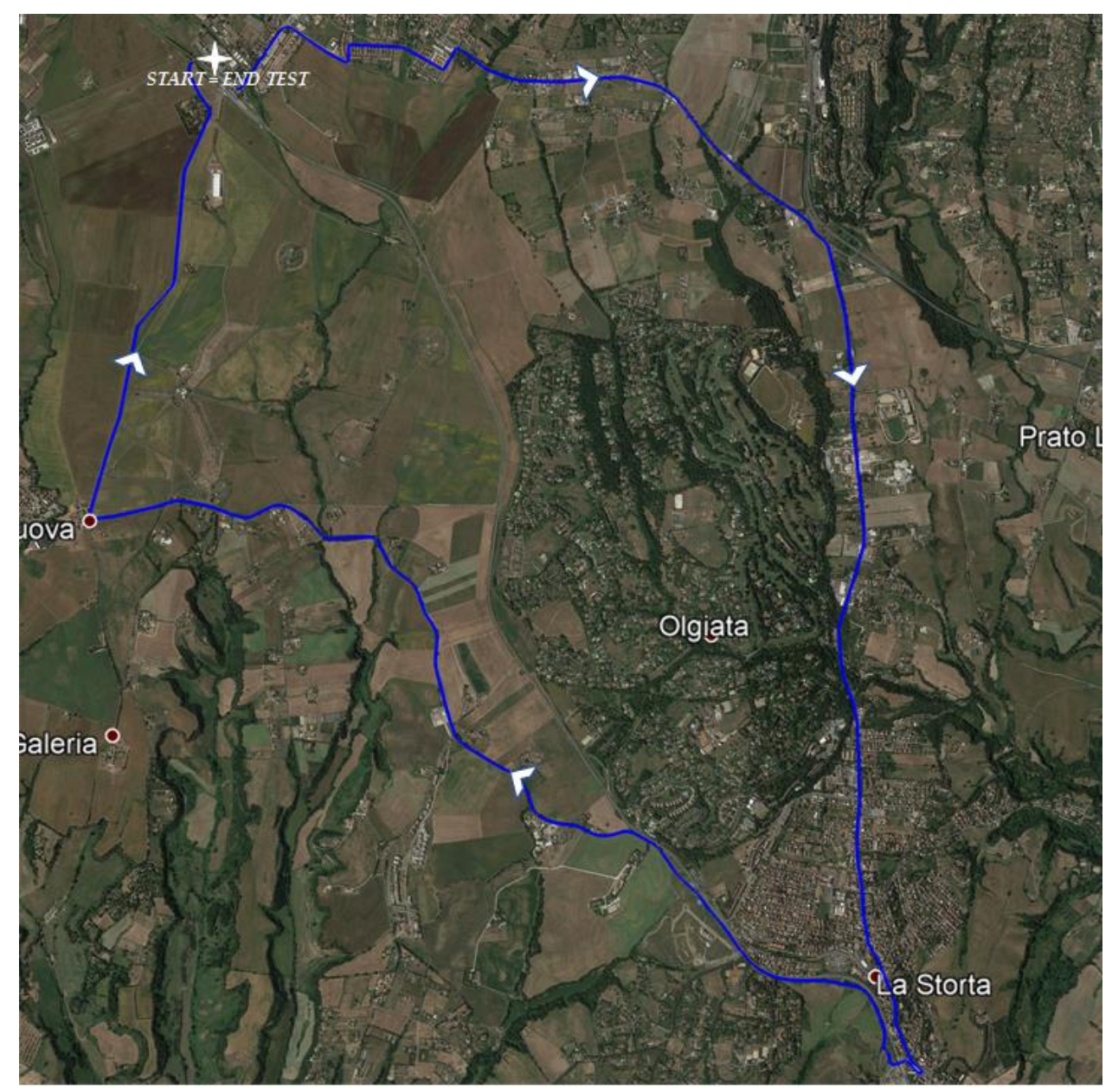

Figure 4. Examined roads and travel direction

Table 5. Characteristics of the roads for system validation

\begin{tabular}{cccccc}
\hline Branch & Length $(\mathbf{m})$ & $\begin{array}{c}\text { Speed limit } \\
(\mathbf{k m} / \mathbf{h})\end{array}$ & Road classification & $\begin{array}{c}\text { Traffic light } \\
\text { (number) }\end{array}$ & $\begin{array}{c}\text { Priority road signs } \\
\text { (number) }\end{array}$ \\
\hline A & 500 & 50 & Urban & NO & NO \\
B & 550 & 30 & Urban & NO & NO \\
C & 100 & 30 & Urban & NO & YES (2) \\
D & 650 & 30 & Urban & NO & YES (1) \\
E & 180 & 30 & Urban & NO & YES (1) \\
F & 2800 & 50 & Urban & NO & YES (1) \\
G & 5700 & 50 & Nonurban & YES (5) & NO \\
H & 230 & 30 & Urban & NO & YES (2) \\
I & 7400 & 50 & NonUrban & NO & YES (1) \\
A & 3600 & 50 & Urban & NO & NO \\
\hline
\end{tabular}

Field tests were carried out without closing roads to traffic and no change in driving behavior was requested to the drivers of test vehicles in which the sensors were placed, so speed value recorded during the measurements were variable in consequence to the road and traffic condition (Figure 5). 


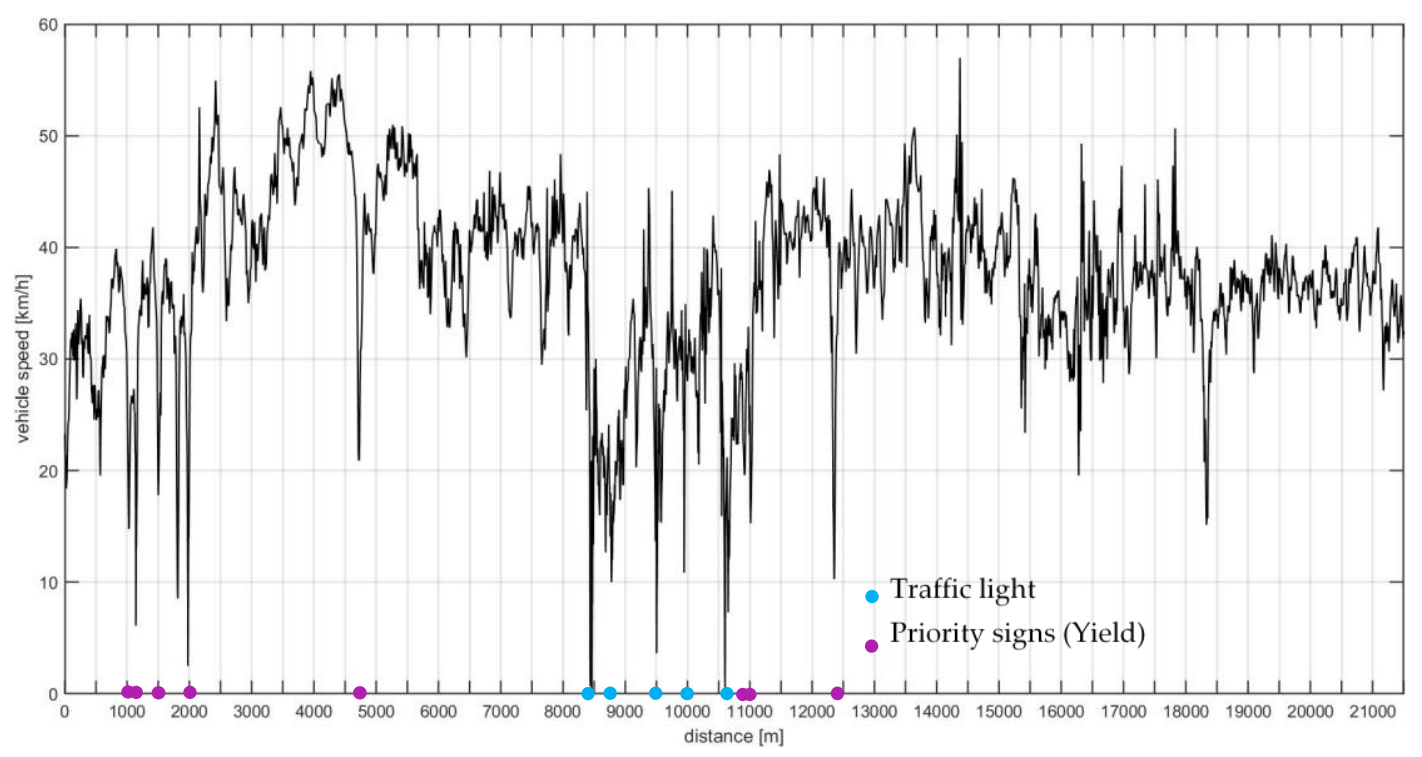

Figure 5. Recorded speed in a test vehicle

In order to have a correct interpretation of the results obtained from the proposed SENSORS\#1 and SENSORS\#2, the ultimate aim is to evaluate the possible use of such devices for pavement condition analysis. In addition, during the measurement campaigns also additional instruments were used:

- LandMark 10 GPSA-150-10-200, a precision measuring instrument [70] with sampling frequency equal to $100 \mathrm{~Hz}$. Post-processing acceleration data recorded from this IMU was aimed to obtain the frequency-weighted vertical acceleration $a_{w z}$ considering analysis times by one second each;

- Mobile Mapping System “Cartesio" with 3 inertial profilers (PaveProf System model) able to measure the road profiles in the left and right wheel paths as well as in the center lane (Figure 6). This system is able to determine IRI and RN considering subsections of 10 meters length each.

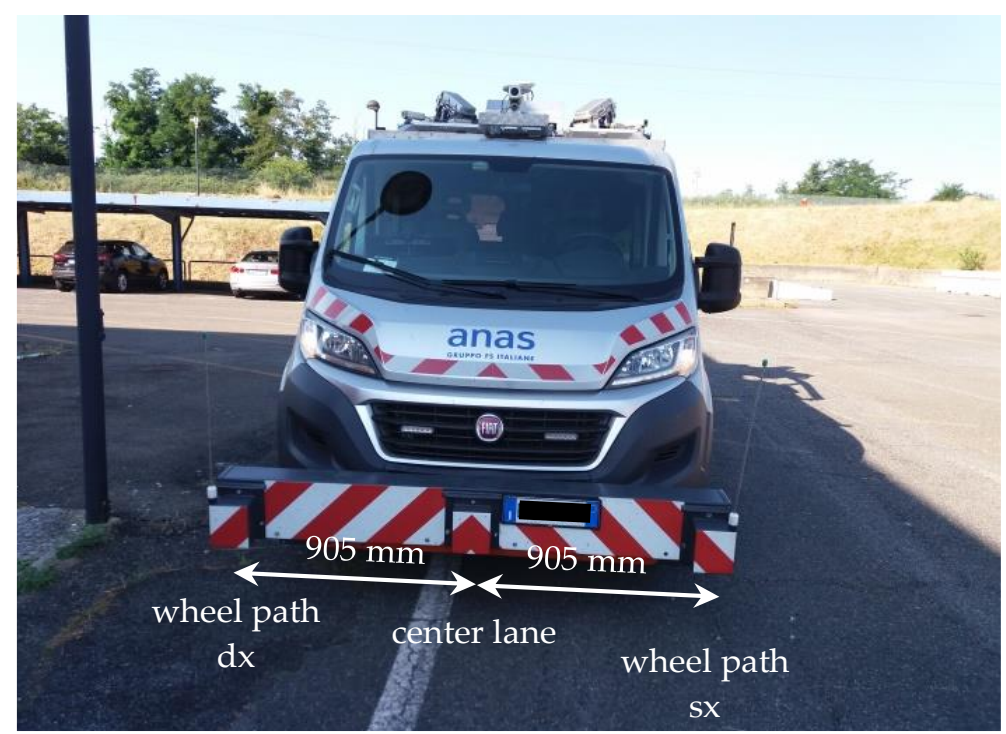

Figure 6. "Cartesio" front view; the profilers are mounted on a bar in front of the vehicle

Information about the vehicles chosen for road tests and the IMUs' position inside these test vehicles have been summarized in the Table 6 . The SENSOR\#1 was positioned on the passenger side floor of a Renault Zoe together with the LANDMARK, while the SENSOR\#2 was installed on "Cartesio" dashboard. 
No particular details (foams, rubber layers or similar) were adopted for fixing the device parts to the box support (only screws, bolts and rubber bands) or to the vehicle dashboard (only double-sided tape), because it is foreseen in the future that these instruments should be able to be simply mounted without special provisions.

Table 6. Characteristics of the IMUs' position inside the vehicle during the tests.

\begin{tabular}{cccc}
\hline Test vehicle & $\begin{array}{c}\text { Average } \\
\text { Test Speed } \\
(\mathbf{k m} / \mathbf{h})\end{array}$ & Inertial Measurement Unit & $\begin{array}{c}\text { Position of the } \\
\text { Inertial Measurement Unit }\end{array}$ \\
\hline Renault Zoe ${ }^{1}$ & 44 & $\begin{array}{c}\text { SENSOR\#1 } \\
\text { LandMark 10 GPSA-150-10-200 }\end{array}$ & $\begin{array}{c}\text { Passenger side floor (Figure 7.a) } \\
\text { Passenger side floor (Figure 7.a) }\end{array}$ \\
\hline Cartesio & 37 & SENSOR\#2 & Dashboard (Figure 7.b) \\
\hline
\end{tabular}

${ }^{1}$ Full electric, Car production year: 2020, Mileage: 190 km

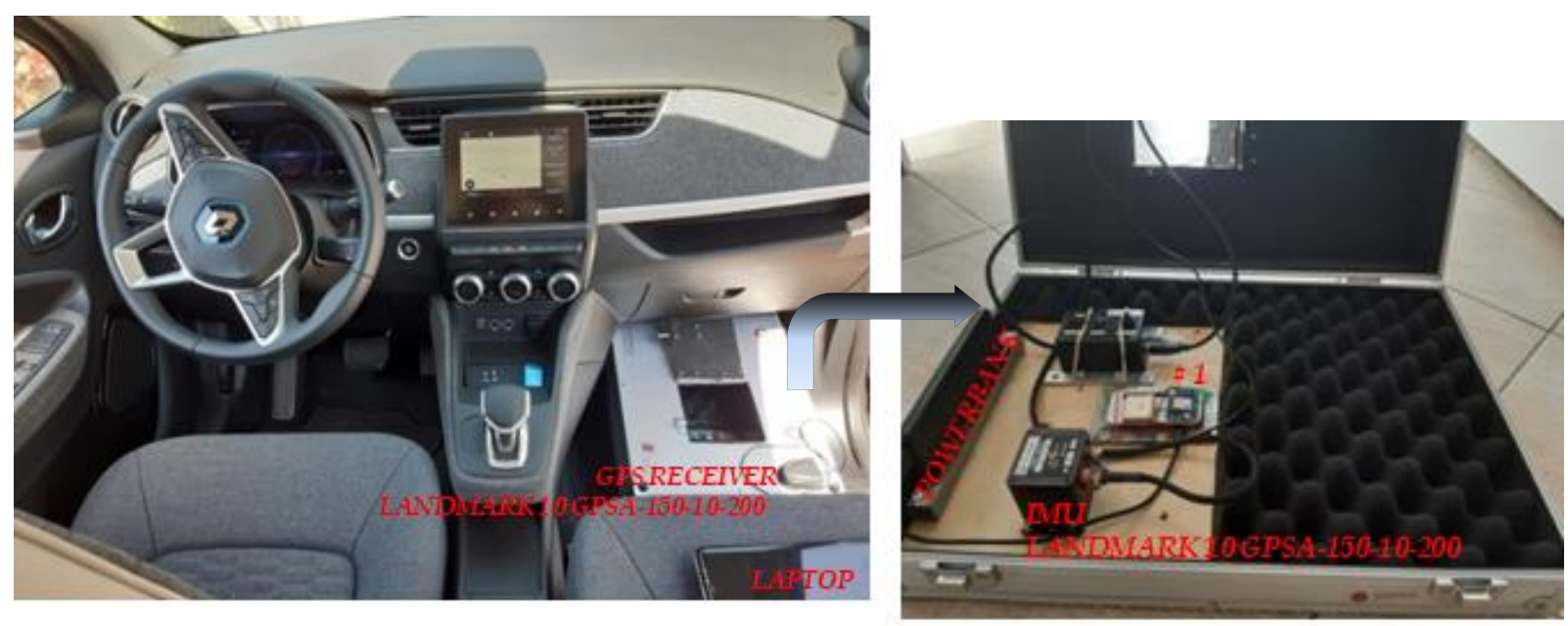

(a)

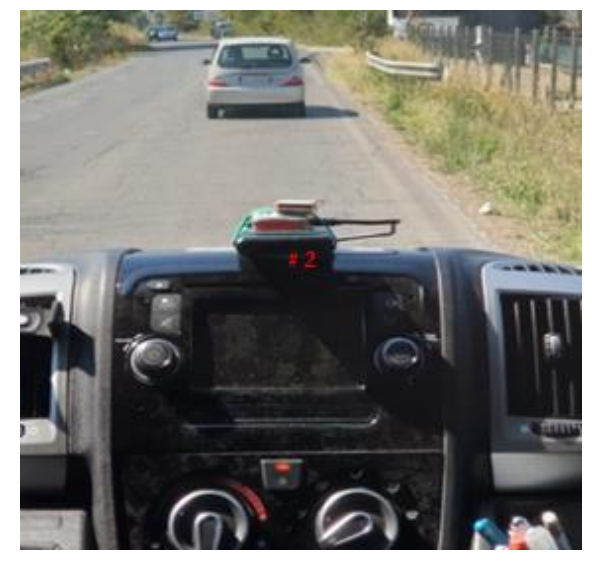

(b)

Figure 7. Position of the SENSOR\#1 inside Renault Zoe (a) and the SENSOR\#2 inside Cartesio (b)

\section{Results and discussion}

A first comparison between the low-cost pavement monitoring SENSOR\#1 and the LANDMARK was in terms of speed values measured during the survey by both devices at the same time (Figure 8).

The two IMUs collected speed values with different frequency rate: $100 \mathrm{~Hz}$ for the LANDMARK and $1 \mathrm{~Hz}$ for the proposed SENSOR\#1. 


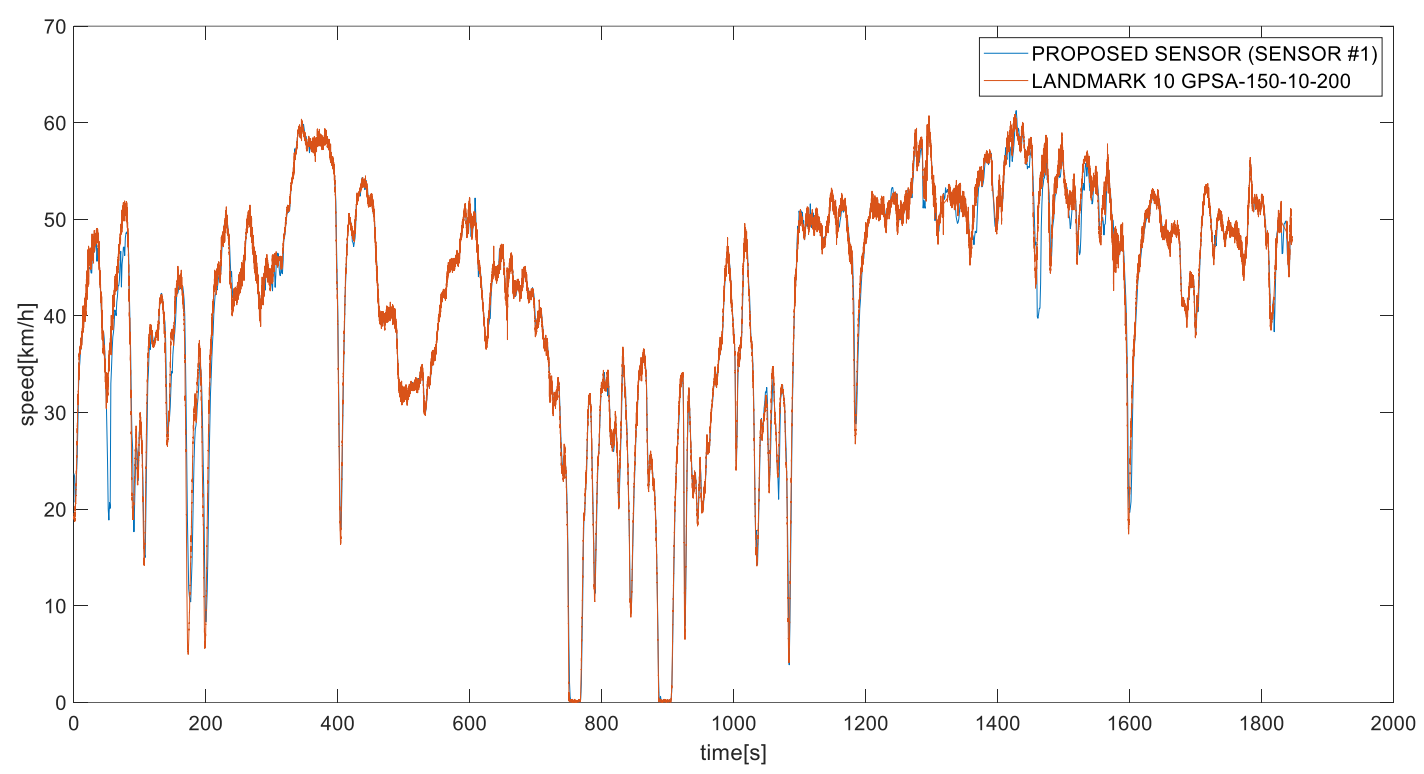

Figure 8. Recorded speed in a test from different instruments placed in the same vehicle: the proposed sensor \#1 (blue) and the LandMark 10 GPSA-150-10-200 (orange).

The comparison between speed values collected by two IMUs at the same time sample showed a good correlation (Figure 9).

In some isolated position, a maximum of $20 \%$ of difference was registered, and, in total, an average total value of only $0.2 \%$ between the two speed values was resulted.

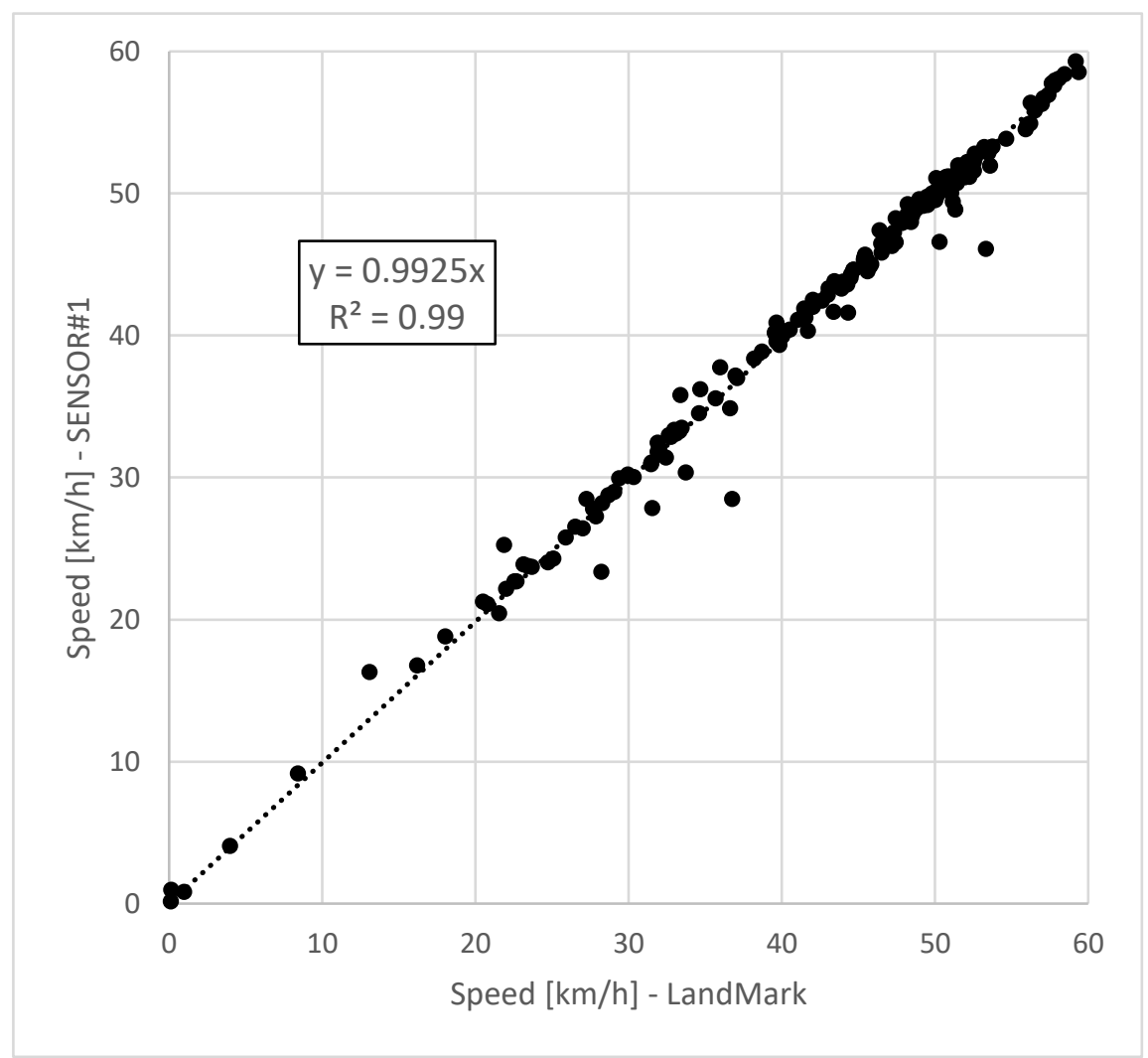

Figure 9. Comparison between speed values collected by LandMark 10 GPSA-150-10-200 and SENSOR\#1 at the same time sample.

After this preliminary comparison, as result of data processing with reference to the examined roads, numerical values of IRI and RN every 10 meters of road section, and the 
whole vibration index $a_{\mathrm{wz}}$ every 1 second of accelerometer signal measured using different IMUs were obtained.

Considering that the vehicle speed in the IMU device tests was variable around 10$16 \mathrm{~m} / \mathrm{s}$, consequently it was possible to determine the measurements of the aforementioned indexes every 1 second and, therefore, approximately every 10-16 m. It was not considered useful, as well as difficult, to exactly match the position in which all the indexes ( $a_{w z}$ obtained with 3 devices, IRI and RN) were available (Figure 10). For this reason, in this preliminary validation phase, fixed and constant long sub-sections $(100 \mathrm{~m})$ of road were considered. The average value of the indexes that the positions were included in a generic section were assumed representative for that sub-section.

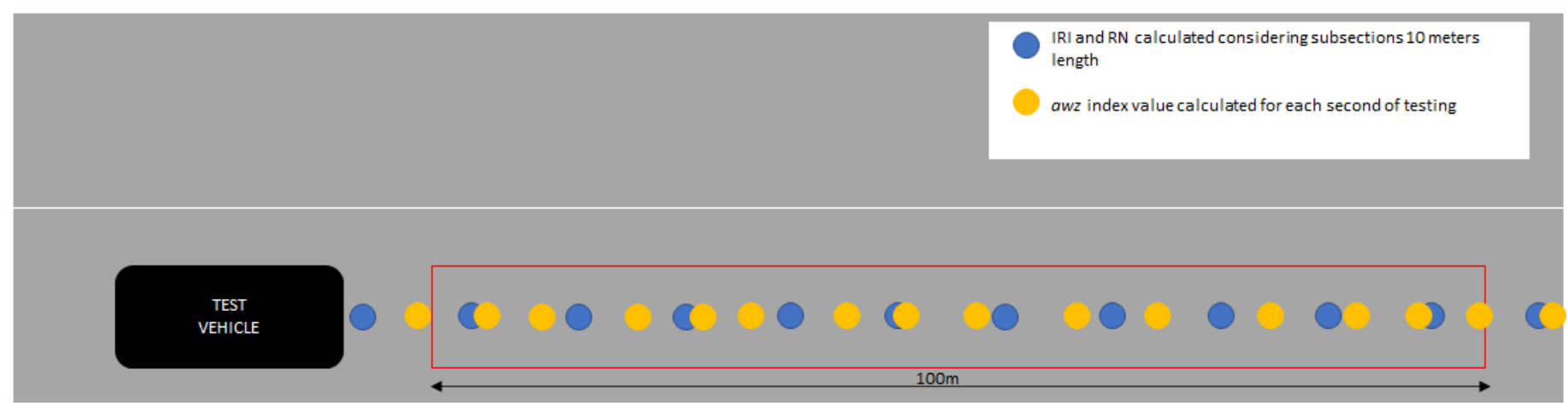

Figure 10. Scheme of the measurement positions along the sub-section of road.

For operational reasons related to the use of the manager's profiler, the considered total section of urban and nonurban road network of $21 \mathrm{~km}$ was measured during the morning of a working day with traffic conditions such as not to always allow to the vehicle the minimum speed for the correct survey of IRI and RN measures.

Consequently, not all the collected measurements were considered useful for validation.

In the $100 \mathrm{~m}$ sub-sections where the speed of the profiler vehicle was greater than the minimum value considered acceptable for the indexes reliability, a subdivision into performance classes with reference to the pavement decay was adopted.

Three different pavement condition categories ("Good", "Fair", and "Poor") derived from related researches $[22,43,47,71]$ were adopted considering the IRI threshold values (Table 7).

Table 7 Pavement condition category associated to the roughness thresholds considered in this paper

\begin{tabular}{cc}
\hline Pavement condition category & IRI $[\mathbf{m m} / \mathbf{m}]$ \\
\hline GOOD & IRI $<3$ \\
FAIR & $3-5$ \\
POOR & IRI $>5$ \\
\hline
\end{tabular}

For this validation phase, it is assumed to consider road sections where the pavement conditions did not vary continuously from a sub-section of $100 \mathrm{~m}$ to the next or the before. On the other hand, the variability of pavement conditions is quite frequent during a normal survey regardless of whatever index is adopted. For this reason, in the usual practice of the pavement monitoring procedure, it is necessary to identify appropriate homogeneous sections in relation to the deterioration conditions surveyed [72].

On the contrary, during the validation procedure, in the entire $21 \mathrm{~km}$ road section, 3 sufficiently long sections (at least equal to $400 \mathrm{~m}$, containing 4 sub-sections) respectively in good, fair and poor conditions were identified (Figure 11 and Table 8). 


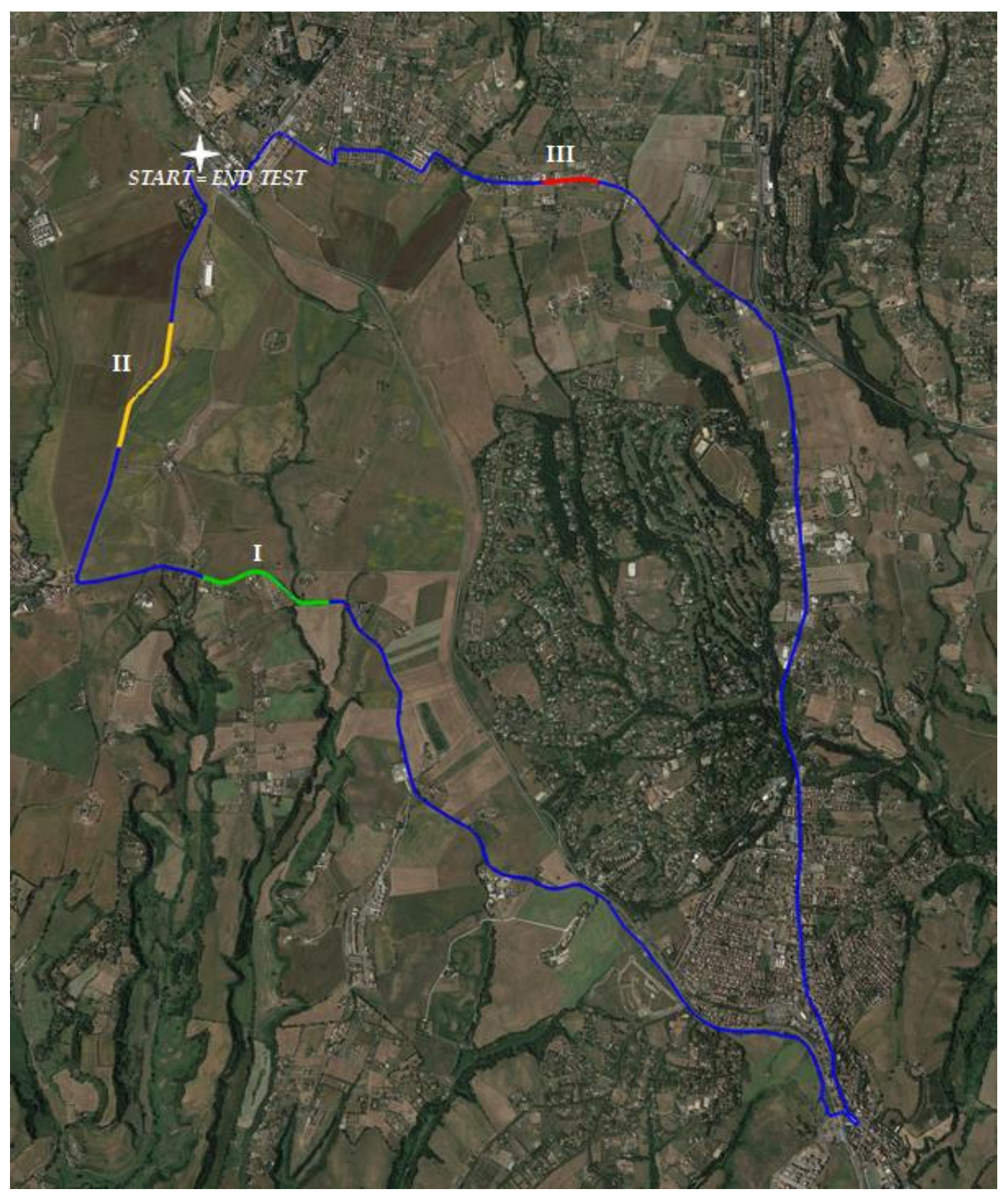

Figure 11. Examined sections for each pavement condition category

Table 8. Characteristics of examined sections

\begin{tabular}{cccccc}
\hline $\begin{array}{c}\text { Section } \\
\text { name }\end{array}$ & Condition & \multicolumn{2}{c}{ Chainage (km) } & $\begin{array}{c}\text { Length } \\
\text { (m) }\end{array}$ & $\begin{array}{c}\text { Number of } \\
\text { sub-sections }\end{array}$ \\
\hline I & Good & $16+300$ & $17+300$ & 1000 & 10 \\
II & Fair & $19+200$ & $20+200$ & 1000 & 10 \\
III & Poor & $2+800$ & $3+200$ & 400 & 4 \\
\hline
\end{tabular}

1 It was calculated the average value of each index per sub-section length of $100 \mathrm{~m}$

5.1. Comparison between SENSOR\#1-awz and LANDMARK-awz

The first step in results analysis process was to find a relationship between $a_{\mathrm{wz}}$ values calculated from data collected by SENSOR\#1 and $a_{\mathrm{wz}}$ values based on data collected by LandMark 10 GPSA-150-10-200 (Figure 12); for clarification purposes it's important to underline that both devices, one next to the other, was inside the same vehicle during the same test. 


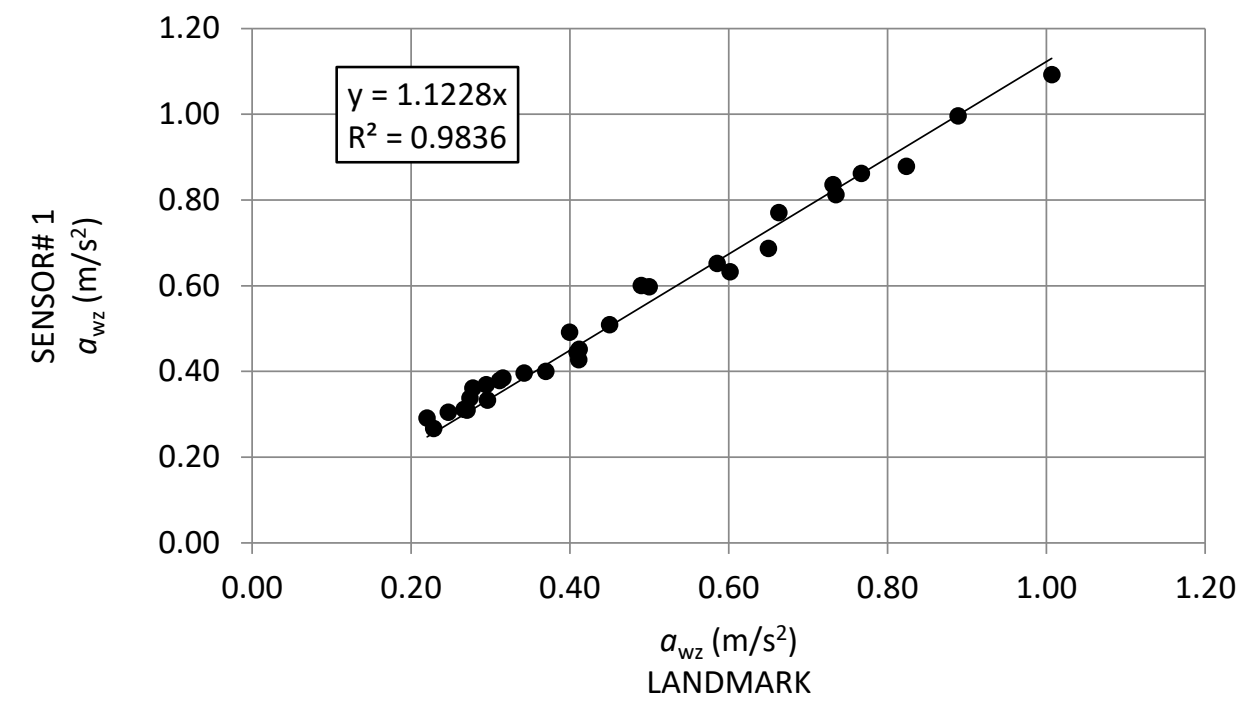

Figure 12. Linear regression between SENSOR\#1- $a_{w z}$ Vs LANDMARK- $a_{w z}$

The regression results showed very good correlations between the frequencyweighted vertical accelerations calculated with the proposed IMU (SENSOR\#1) and ones in the reference IMU (LANDMARK). The coefficient of determination $\left(\mathrm{R}^{2}=0.98\right)$ indicates a strong concordance between measurements from the SENSOR\#1 and the LandMark10, although the former presented a smaller accuracy and an it were obtained $a_{w z}$ index values about $10 \%$ greater than the ones of reference IMU.

\subsection{Comparison between SENSOR\#1-awz and SENSOR\#2-awz}

This paragraph focuses on the comparison between the frequency-weighted vertical acceleration values based on data collected from SENSOR\#1 and SENSOR\#2 respectively (Figure 13).

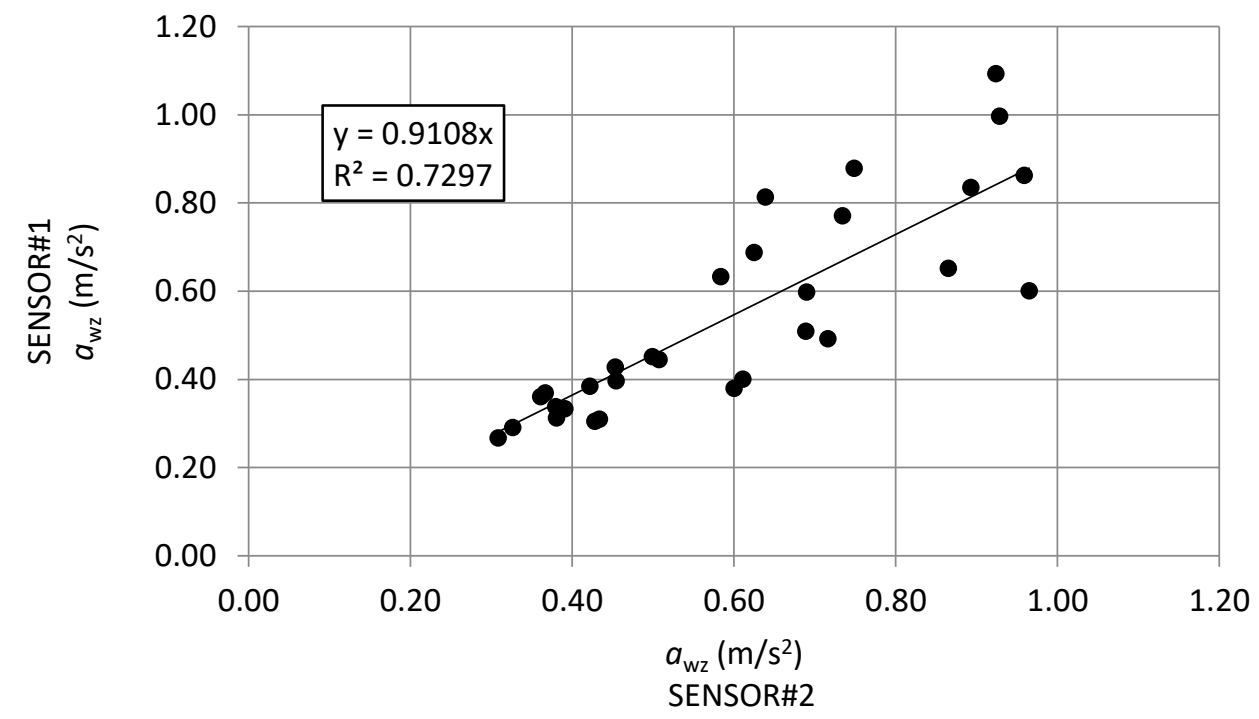

Figure 13. Linear regression SENSOR\#1- $a_{w z}$ Vs SENSOR\#2- $a_{w z}$

The dispersion of data points around the regression line and a non-unit slope are in agreement that the two identical prototypes were placed in different positions inside vehicles which in turn differed in the physical and mechanical characteristics and also in the recorded speeds: these factors significantly influence the final values of $a_{\mathrm{wz}}$ index.

5.3. Comparison between $a_{w z} v s$ IRI and $a_{w z} v s R N$ 
For the purpose of this research, it is also important the comparison between $a_{\mathrm{wz}}$ index, calculated from data collected in the field tests respectively by SENSOR\#1 and SENSOR\#2, and the values of International Roughness Index and Ride Number related to the data acquired by "Cartesio" (Figure 14)
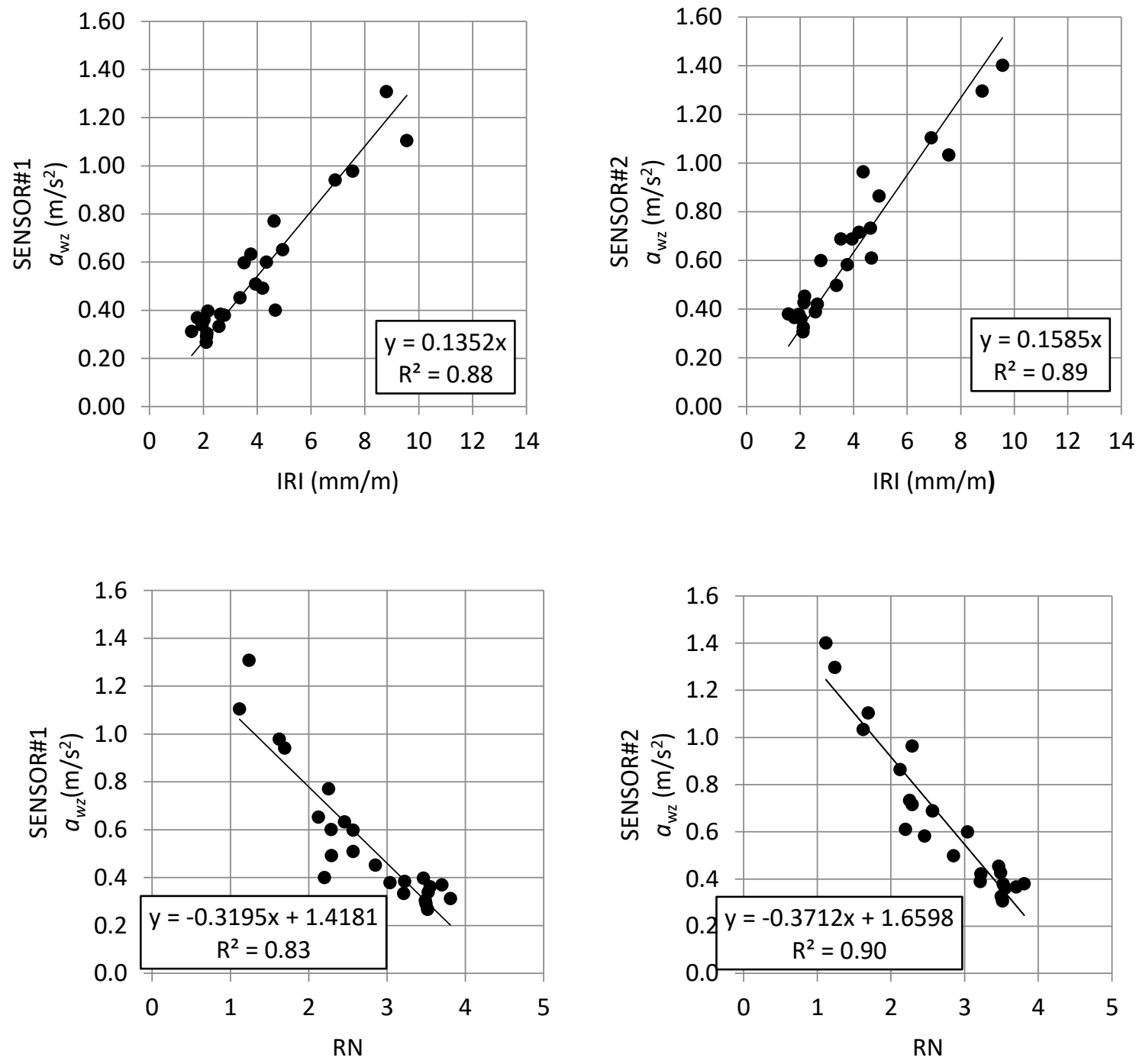

Figure 14. Linear regression $a_{\mathrm{wz}}-$ IRI vs $a_{\mathrm{wz}}-\mathrm{RN}$

As shown in Figure 14, the calculated $a_{w z}$ by the proposed system and the indexes determined by RSP are highly correlated in all cases with the coefficient of determination more than 0.83 . Considering the $a_{w z}$ determined with acceleration data measured by IMU located in the same vehicle where the RN were measured, a higher coefficient of determination was obtained.

\section{Conclusions}

This work aimed to verify the feasibility of using a Raspberry-based IMU device for monitoring the road pavement condition in urban areas. Tests were carried out using two identical Raspberry-based prototypes along about $21 \mathrm{~km}$ of urban and nonurban roads with flexible pavement located, and the validation was performed employing as reference concomitant measurements by the IMU LandMark10+GPS and the "Cartesio" Mobile Measurement System vehicle. 
Considering the comfort index $a_{w z}$ in accordance with ISO 2631 standard, the results showed very good correlations between the frequency-weighted vertical accelerations calculated with the proposed IMU (SENSOR\#1) and ones in the reference IMU. The coefficient of determination $\left(\mathrm{R}^{2}=0.98\right)$ indicates a strong concordance between measurements from the SENSOR\#1 and the LandMark10, although the former presented a smaller accuracy and an $a_{w z}$ index value 10 per cent greater than the reference IMU. Besides, the comparison between the two Raspberry-based devices yielded a coefficient of determination $\left(\mathrm{R}^{2}=0.73\right)$, with discrepancy explained by the fact that the sensors were installed in different vehicles and different positions inside each vehicle. This leads to an initial indication of how speed and the vehicle's physical and mechanical characteristics may affect the estimate of the comfort indicator $a_{w z}$.

Furthermore, the evaluation of the correlation between data gathered by "Cartesio" (IRI and RN) and the $a_{w z}$ indexes calculated by SENSOR\#1 and SENSOR\#2 revealed a good consistency between the measurements. The correlation coefficients were in all arrangements greater than 0.82 , implying a high correlation between the reference data and the measurements obtained from the proposed devices. It must be emphasized that the greatest correlation $\left(R^{2}=0.90\right)$ was, as expected, verified between $R N$ and the frequencyweighted vertical accelerations calculated from the SENSOR\#2 located inside the "Cartesio".

It may be concluded that the proposed sensor can be considered a valuable tool for a quick, low-cost road survey if considered that the repeatability of the results is conditioned by the speed and physical-mechanical characteristics of the vehicle. The proposed study is not intended to establish the Raspberry platform on the same level as the other precision devices. Instead, the correct interpretation is to provide an affordable tool that does not require dedicated staff and that can be easily installed in public service vehicles, local public transport vehicles, and even two-wheeled vehicles, widening the range of monitorable pavements (including sidewalks and bike lanes).

Since the described device is a prototype, it could be possible to perform improvements such as its integration with a GSM unit to transmit data directly to a server. In this context, for reasons of repeatability, information such as type of vehicle, position inside the vehicle, the fixing system and, finally, the speed at which the recording was carried out would be mandatory to enable a weighted evaluation of the measurements. Remaining within the scope of instrumentation refinement, it could be envisaged to develop a GIS system for the positioning and cataloguing of measurements in terms of $a_{w z}$ index in order to enable better integration with traditional measurement systems.

Author Contributions: “Conceptualization, G.L. and F.A.; methodology, G.L.; software, R.O. and S.B.; validation, G.L. and S.B.; formal analysis, G.L. and S.B.; investigation, G.L., R.O. and S.B.; resources, G.L.; data curation, G.L.; writing - original draft preparation, G.L., F.A., R.O. and S.B.; writing - review and editing, G.L.; visualization, S.B.; supervision, G.L. and F.A.; project administration, G.L. and F.A.; funding acquisition, G.L. and F.A. All authors have read and agreed to the published version of the manuscript."

Funding: "This research was funded by Sapienza, University of Rome, grant number RM11715C773C3779, and financed in part by the Coordenação de Aperfeiçoamento de Pessoal de Nível Superior (CAPES), Brazil, Finance Code 001".

Institutional Review Board Statement: Not applicable.

Informed Consent Statement: Not applicable.

Acknowledgments: The Authors wish thank the Laboratory of Road Material and Maintenance of the Italian National Road Agency (Centro Sperimentale Strade di Cesano di ANAS S.p.A. Gruppo Ferrovie dello Stato Italiane) and in particular Eng. Marcello De Marco and Eng. Ferdinando Mattia for the collaboration during the road tests with "Cartesio" and for sharing the pavement monitoring data for this research.

Conflicts of Interest: "The authors declare no conflict of interest." 


\section{References}

1. Hudson, W.R.; Uddin, W.; Haas, R.C. Infrastructure Management: Integrating Design, Construction, Maintenance, Rehabilitation and Renovation; 1997; ISBN 978-0-07-030895-4.

2. Uddin, W.; Hudson, W.; Haas, R. Public Infrastructure Asset Management, Second Edition; 2013; ISBN 0071820124.

3. Bonin, G.; Polizzotti, S.; Loprencipe, G.; Folino, N.; Oliviero Rossi, C.; Teltayev, B.B. Development of a road asset management system in kazakhstan. In Transport Infrastructure and Systems - Proceedings of the AIIT International Congress on Transport Infrastructure and Systems, TIS 2017; CRC Press/Balkema: CRC Press/Balkema P.O. Box 11320, 2301 EH Leiden, The Netherlands, 2017; pp. 537-545 ISBN 9781138030091.

4. Kulkarni, R.B.; Miller, R.W. Pavement Management Systems: Past, Present, and Future. Transp. Res. Rec. 2003, 65-71.

5. Zaabar, I.; Chatti, K. Estimating vehicle operating costs caused by pavement surface conditions. Transp. Res. Rec. 2014, 2455, $63-76$.

6. Wang, T.; Harvey, J.; Lea, J.; Kim, C. Impact of pavement roughness on vehicle free-flow speed. J. Transp. Eng. $2014,140$.

7. Múčka, P. Vibration Dose Value in Passenger Car and Road Roughness. J. Transp. Eng. Part B Pavements 2020, $146,04020064$.

8. Popoola, M.O.; Apampa, O.A.; Adekitan, O. Impact of Pavement Roughness on Traffic Safety under Heterogeneous Traffic Conditions. Niger. J. Technol. Dev. 2020, 17, 13-19.

9. Mora Otto Alfonso; Figuero, M.; Velosa, C.N.; Alfonso Daniel Effect of road quality on fuel consumption and the generation of externalities derived from transport. Case of study: Barranquilla, Colombia. Espacios 2020, 41, 5.

10. Li, T. Influencing parameters on tire-pavement interaction noise: Review, experiments, and design considerations. Designs 2018, 2, 1-69.

11. Cantisani, G.; Fascinelli, G.; Loprencipe, G. Urban Road Noise: The Contribution of Pavement Discontinuities. In Proceedings of the ICSDEC 2012: Developing the Frontier of Sustainable Design, Engineering, and Construction - Proceedings of the 2012 International Conference on Sustainable Design and Construction; 2013; pp. 327-334.

12. Loprencipe, G.; Zoccali, P. Ride quality due to road surface irregularities: Comparison of different methods applied on a set of real road profiles. Coatings 2017, 7.

13. Papageorgiou, G. Appraisal of road pavement evaluation methods. J. Eng. Sci. Technol. Rev. 2019, 12, $158-166$.

14. Shtayat, A.; Moridpour, S.; Best, B.; Shroff, A.; Raol, D. A review of monitoring systems of pavement condition in paved and unpaved roads. J. Traffic Transp. Eng. (English Ed. 2020, 7, 629-638.

15. Wambold, J.C. The measurement and data analysis used to evaluate highway roughness. Wear 1979, 57, 117-125.

16. Múčka, P. Current approaches to quantify the longitudinal road roughness. Int. J. Pavement Eng. 2016, 17, 659-679.

17. Sayers, M.W.; Karamihas, S.M. The little book of profiling; 1998;

18. Chen, D.; Hildreth, J.; Mastin, N. Determination of IRI Limits and Thresholds for Flexible Pavements. J. Transp. Eng. Part B Pavements 2019, 145, 04019013.

19. Tehrani, S.S.; Cowe Falls, L.; Mesher, D. Road users' perception of roughness and the corresponding IRI threshold values. Can. J. Civ. Eng. 2015, 42, 233-240.

20. Chen, X.; Zhu, H.; Dong, Q.; Huang, B. Optimal thresholds for pavement preventive maintenance treatments using LTPP data. J. Transp. Eng. 2017, 143.

21. Múčka, P. Road Roughness Limit Values Based on Measured Vehicle Vibration. J. Infrastruct. Syst. 2017, 23, 04016029.

22. Yu, J.; Chou, E.Y.J.; Yau, J.-T. Development of Speed-Related Ride Quality Thresholds Using International Roughness Index. Transp. Res. Rec. J. Transp. Res. Board 2006, 1974, 47-53.

23. Loprencipe, G.; Zoccali, P.; Cantisani, G. Effects of vehicular speed on the assessment of pavement road roughness. Appl. Sci. 2019, 9 .

24. Gong, J.; Zhou, H.; Gordon, C.; Jalayer, M. Mobile terrestrial laser scanning for highway inventory data collection. In Proceedings of the Congress on Computing in Civil Engineering, Proceedings; 2012; pp. 545-552. 
25. Madeira, S.; Gonçalves, J.A.; Bastos, L. Sensor integration in a low cost land mobile mapping system. Sensors 2012, 12, 29352953.

26. Rajamohan, D.; Gannu, B.; Rajan, K.S. MAARGHA: A prototype system for road condition and surface type estimation by fusing multi-sensor data. ISPRS Int. J. Geo-Information 2015, 4, 1225-1245.

27. Chen, K.; Lu, M.; Fan, X.; Wei, M.; Wu, J. Road condition monitoring using on-board three-axis accelerometer and GPS sensor. In Proceedings of the Proceedings of the 2011 6th International ICST Conference on Communications and Networking in China, CHINACOM 2011; 2011; pp. 1032-1037.

28. Zang, K.; Shen, J.; Huang, H.; Wan, M.; Shi, J. Assessing and mapping of road surface roughness based on GPS and accelerometer sensors on bicycle-mounted smartphones. Sensors (Switzerland) 2018, 18.

29. Du, Y.; Liu, C.; Wu, D.; Jiang, S. Measurement of international roughness index by using Z -axis accelerometers and GPS. Math. Probl. Eng. 2014, 2014.

30. González, A.; O’Brien, E.J.; Li, Y.Y.; Cashell, K. The use of vehicle acceleration measurements to estimate road roughness. Veh. Syst. Dyn. 2008, 46, 483-499.

31. Amador-Jiménez, L.; Matout, N. A low cost solution to assess road 's roughness surface condition for Pavement Management. TRB 2014 Annu. Meet. 2014, 2424, 16.

32. Harikrishnan, P.M.; Gopi, V.P. Vehicle Vibration Signal Processing for Road Surface Monitoring. IEEE Sens. J. 2017, 17, 51925197.

33. Islam, S.; Buttlar, W.G.; Aldunate, R.G.; Vavrik, W.R. Measurement of pavement roughness using android-based smartphone application. Transp. Res. Rec. 2014, 2457, 30-38.

34. Strazdins, G.; Mednis, A.; Kanonirs, G.; Zviedris, R.; Selavo, L. Towards Vehicular Sensor Networks with Android Smartphones for Road Surface Monitoring. In Proceedings of the Second International Workshop on Networks of Cooperating Objects (CONET). Chicago, 1-4; 2011.

35. Douangphachanh, V.; Oneyama, H. Exploring the use of smartphone accelerometer and gyroscope to study on the estimation of road surface roughness condition. In Proceedings of the ICINCO 2014 - Proceedings of the 11th International Conference on Informatics in Control, Automation and Robotics; 2014; Vol. 1, pp. 783-787.

36. Douangphachanh, V.; Oneyama, H. Using Smartphones to Estimate Road Pavement Condition. In Proceedings of the Proceedings of the International Symposium of Next Generation Infrastructure, 1-4 October 2013, SMART Infrastructure Facility, University of Wollongong, Australia; Campbell P. and Perez P., Ed.; 2014.

37. Tai, Y.; Chan, C.; Hsu, J.Y. Automatic Road Anomaly Detection Using Smart Mobile Device. In Proceedings of the Proceedings of the 2010 Conference on Technologies and Applications of Artificial Intelligence (TAAI2010); 2010.

38. Vittorio, A.; Vittoria, C.M.; Guido, D.; Demetrio, C.F.; Vincenzo, P.G.; Iuele, T.; Rosolino, V. A mobile application for road surface quality control: UNIquALroad. Procedia - Soc. Behav. Sci. 2012, 54, 1135 - 1144.

39. Singh, G.; Bansal, D.; Sofat, S.; Aggarwal, N. Smart patrolling: An efficient road surface monitoring using smartphone sensors and crowdsourcing. Pervasive Mob. Comput. 2017, 40, 71-88.

40. Lars Forslöf; Hans Jones Roadroid: Continuous Road Condition Monitoring with Smart Phones. J. Civ. Eng. Archit. 2015, 9.

41. Alessandroni, G.; Klopfenstein, L.C.; Delpriori, S.; Dromedari, M.; Luchetti, G.; Paolini, B.D.; Seraghiti, A.; Lattanzi, E.; Freschi, V.; Carini, A.; et al. SmartRoadSense: Collaborative road surface condition monitoring. In Proceedings of the UBICOMM 2014 - 8th International Conference on Mobile Ubiquitous Computing, Systems, Services and Technologies; 2014; pp. 210-215.

42. Lima, L.C.; Amorim, V.J.P.; Pereira, I.M.; Ribeiro, F.N.; Oliveira, R.A.R. Using crowdsourcing techniques and mobile devices for asphaltic pavement quality recognition. In Proceedings of the Brazilian Symposium on Computing System Engineering, SBESC; 2016; Vol. 0, pp. 144-149.

43. Cantisani, G.; Loprencipe, G. Road Roughness and Whole Body Vibration: Evaluation Tools and Comfort Limits. J. Transp. 
Eng. 2010, 136, 818-826.

44. Múčka, P. International Roughness Index specifications around the world. Road Mater. Pavement Des. 2017, 18, 929-965.

45. Abudinen, D.; Fuentes, L.G.; Muñoz, J.S.C. Travel quality assessment of urban roads based on international roughness index: Case study in Colombia. Transp. Res. Rec. 2017, 2612, 1-10.

46. La Torre, F.; Ballerini, L.; Di Volo, N. Correlation between longitudinal roughness and user perception in urban areas. Transp. Res. Rec. 2002, 131-139.

47. Kırbaş, U.; Karaşahin, M. Investigation of ride comfort limits on urban asphalt concrete pavements. Int. J. Pavement Eng. 2018, 19, 949-955.

48. Fichera, G.; Scionti, M.; Garescì, F. Experimental correlation between the road roughness and the comfort perceived in bus cabins. SAE Tech. Pap. 2007.

49. Ahlin, K.; Granlund, N.O.J. Relating Road Roughness and Vehicle Speeds to Human Whole Body Vibration and Exposure Limits. Int. J. Pavement Eng. 2002, 3, 207-216.

50. Ahlin, K.; Granlund, J. International roughness index, IRI, and ISO 2631 vibration evaluation. Washingt. DC Transp. Res. Board $2001,6,7$.

51. ISO2631-1 Mechanical vibration and shock - Evaluation of human exposure to whole-body vibration - Part 1: General requirements.; 1997;

RASPBERRY PI FOUNDATION Raspberry Pi Zero W - Technical Specifications Available online: https://www.raspberrypi.org/products/raspberry-pi-zero-w/ (accessed on Mar 29, 2021).

ISO:8608-2016 Mechanical vibration - Road surface profiles - Reporting of measured data; 2016;

54. 13473-4:2008, I.-I. Characterization of pavement texture by use of surface profiles - Part 4: Spectral analysis of surface profiles; 2008;

55. Kim, W.Y.; G., Y.; Tae K., C.; Song, I.H.; Cho, Y.S.; Jae, J.H.· W.G.J.· J.W.L.· Signals and Systems with Matlab; Springer Dordrecht Heidelberg London New York, Ed.; 2015; ISBN 9783540929536.

56. Sayers, M.W. On the calculation of international roughness index from longitudinal road profile. Transp. Res. Rec. 1995, 1-12.

57. Chen, C.; Zhang, J. Comparisons of IRI-Based Pavement Deterioration Prediction Models Using New Mexico Pavement Data. 2011, 4594-4603.

58. Al-Suleiman, T.I.; Shiyab, A.M.S. Prediction of Pavement Remaining Service Life Using Roughness Data - Case Study in Dubai. Int. J. Pavement Eng. 2003, 4, 121-129.

59. ASTME1926:08 Standard Practice for Computing International Roughness Index of Roads from Longitudinal Profile Measurements. 2013, i, 1-16.

60. Janoff, M.S.; Nick, J.B.; Davit, P.S.; Hayhoe, G.F. Pavement Roughness and Rideability. Natl. Coop. Highw. Res. Progr. Rep. 1985.

61. ASTM E1489 - 98 Standard Practice for Computing Ride Number of Roads from Longitudinal Profile Measurements Made by an Inertial Profile Measuring Device; 1998;

Titterton, D.; Weston, J. Strapdown Inertial Navigation Technology; Institution of Engineering and Technology, 2004; ISBN 9780863413582.

63. Invensense MPU-9250 Product Specification Revision 1.1; 2019;

64. Bosch BMP280: Datasheet. Digit. Presusure Sens; 2015;

65. Richards Tech RTIMULib2 - a versatile C++ and Python 9-dof, 10-dof and 11-dof IMU library GitHub RTIMULib/RTIMULib2 Available online: https:/github.com/RTIMULib/RTIMULib2 (accessed on Mar 29, 2021).

66. Modules, U.N.-6 u-blox 6 G. Www.U-Blox.Com.

67. van Diggelen, F. A-GPS: Assisted GPS, GNSS, and SBAS. Artech Housh 2009, 400.

68. Hofmann-Wellenhof, B.; Lichtenegger, H.; Wasle, E. GNSS - GPS, GLONAS, GALILEO and more; 2008; ISBN 9783211730126.

69. Braam, M.P.G. client-a library for polling gpsd in P. GitHub - MartijnBraam/gpsd-py3: Python 3 GPSD client Available online: 
https://github.com/MartijnBraam/gpsd-py3 (accessed on Mar 29, 2021).

70. Zoccali, P.; Loprencipe, G.; Lupascu, R.C. Acceleration measurements inside vehicles: Passengers' comfort mapping on railways. Meas. J. Int. Meas. Confed. 2018, 129, 489-498.

71. Abulizi, N.; Kawamura, A.; Tomiyama, K.; Fujita, S. Measuring and evaluating of road roughness conditions with a compact road profiler and ArcGIS. J. Traffic Transp. Eng. (English Ed. 2016, 3, 398-411.

72. Cafiso, S.; Di Graziano, A. Definition of Homogenous Sections in Road Pavement Measurements. Procedia - Soc. Behav. Sci. 2012, 53, 1069-1079. 